\title{
HLA-DEPENDENT TNF SECRETORY RESPONSE MAY PROVIDE AN IMMUNOGENETIC LINK BETWEEN PRE-ECLAMPSIA AND TYPE 1 DIABETES MELLITUS
}

\author{
DAVID C. KILPATRICK \\ Department of Transfusion Medicine, 2 Forrest Road, Edinburgh, EHI 2QN, U.K.
}

\section{SUMMARY}

Tumour necrosis factor (TNF) may be relevant to the pathogenesis of both pre-eclampsia and type 1 diabetes, and there is evidence than human TNF $\alpha$ responses to stimuli are HLA-DR dependent. To test the hypothesis that pre-eclampsia and diabetes may share a common immunogenetic susceptibility, 92 pre-eclampsia patients were compared with 264 general population controls. The relative frequencies of individual HLA-DR antigens in pre-eclamptics were found to correlate with reported relative TNF $\alpha$ responses for those antigens. Moreover, putative high responder HLA-DR 1, DR3 and DR4 alleles were significantly $(\mathrm{p}<0.001)$ more frequent in pre-eclampsia patients $(79 \%)$ than in controls $(59 \%)$. This hypothesis could explain the weak association between pre-eclampsia and diabetes and may help resolve the apparently conflicting literature on HLA in pre-eclampsia.

KEY WORDS Tumour necrosis factor HLA-DR Diabetes Pre-eclampsia

\section{INTRODUCTION}

Studies on pre-eclampsia have thrown up many conflicting ideas. There is undoubtedly a genetic component, but its nature us unclear (Cooper et al., 1993). Data on HLA relationships have been particularly inconsistent (Cooper et al., 1993). Our own finding of an association between pre-eclampsia and sharing of HLA-DR4 between fetus and mother (Kilpatrick et al., 1990) has never been confirmed or refuted, but others have failed to confirm an association with maternal HLA-DR4 or to implicate linkage disequilibrium between maternal HLA-DR4 and the putative pre-eclampsia susceptibility gene (Wilton et al., 1991; Hayward et al., 1990). Nevertheless, the association with maternal HLA-DR4 is the only HLA association that has been reported from two independent laboratories (Cooper et al., 1993; Simon et al., 1988).

Diabetics are at increased risk of pre-eclampsia (Garner et al., 1990), and conversely, women with pre-eclampsia are more likely than normotensive women to experience type 1 diabetes in later life (Dahlquist and Kallen, 1992). It is well established that HLA-DR4 is positively associated with insulin dependent diabetes mellitus, and it is possible these clinically unrelated diseases share a common immunogenetic susceptibility marker.

A totally separate line of investigation could also link pre-eclampsia with diabetes. The oxidative stress hypothesis attributes a central role to tumour necrosis factor (TNF) in the pathogenesis of pre-eclampsia (Stark, 1993). Human TNF secretion in response to lipopolysaccharide is HLA-Class II dependent (Santamaria et al., 1989). Pociot et al. (1993) have investigated the relationship between TNF release and individual HLA-DR 
alleles. HLA-DR1, 3 and 4 individuals were found to be high responders, while HLADR2 and 5 individuals were low responders. Pociot et al. suggested that TNF plays a role in the pathogenesis of type 1 diabetes and is linked to the HLA associations of that disease. I have therefore re-analysed HLA-DR data for pre-eclampsia patients and controls to test the hypothesis that pre-eclampsia may also be associated with the DR alleles linked to a high TNF response.

\section{METHODS}

HLA-DR typing was previously carried out on 92 unrelated women whose pregnancies were complicated by proteinuric pre-eclampsia meeting the criteria for gestational proteinuric hypertension (Kilpatrick et al., 1990). Control data representing the general population were obtained from 132 women and their husbands after normal pregnancies (Jazwinska et al., 1987). Data on TNF $\alpha$ secretion as a function of HLA-DR type was taken from Pociot et al. (1993).

Regression analysis was performed by Student's t-test. 2 x 2 analyses were conducted by the $\mathrm{x}^{2}$ test and Fisher's exact test.

\section{RESULTS}

The relative TNF $\alpha$ secretory capacity calculated from Pociot et al. (1993) closely resembles the relative frequency of HLA-DR alleles in pre-eclamptic patients (Table 1). The DR 5,6 and 8 antigens have been grouped together because serological typing with the antisera available at the time did not distinguish accurately between those specificities, and all three were associated with a below-average TNF $\alpha$ response. Thus analysed, there was a striking correlation $(r=0.78)$ which approached statistical significance $(\mathrm{p}<0.07)$.

When the HLA data were analysed to compare the proportion of women with preeclampsia ( $n=92)$ with HLA DR 1 or 3 or $4(79 \%)$ to the corresponding proportion in the general population $\left(59 \%\right.$ of 264 controls), the difference was highly significant $\left(x^{2}=\right.$ 12.6; $\mathrm{p}<0.001$ ). Even when all patients and controls possessing HLA-DR4 were excluded from the analysis, the putative high $\mathrm{TNF} \alpha$ responders were still significantly overrepresented (Table 2).

\section{DISCUSSION}

These results clearly confirm an association between pre-eclampsia and the group of HLA-DR specificities found in association with high TNF $\alpha$ responders. This analysis and interpretation relies on the data of Pociot and coworkers, but other groups have also found DR3 to be associated with high, and DR2 to be associated with low, TNF $\alpha$ responders (Bendtzen et al., 1988; Jacob et al., 1990; Peces et al., 1995).

This relationship not only supports a role for TNF in the pathogenesis of preeclampsia, but may help explain some of the confusion in the literature of HLA and preeclampsia. It is not a single HLA-DR specificity that would be over-represented in the disease, but a group of antigens. which might occur in varying proportions in different series of patients. The putative HLA-DR4 association in particular has been called into question, and therefore the data were analysed separately after the withdrawal of all DR- 
Table 1. Pre-eclampsia and TNF response related to HLA-DR.

\begin{tabular}{ccc}
\hline HLA-DR specificity & $\begin{array}{l}\text { Relative frequency } \\
\text { in pre-eclampsia* }\end{array}$ & $\begin{array}{l}\text { Relative TNF } \alpha^{*} \text { response }^{\#} \\
1\end{array}$ \\
\hline 2 & 1.81 & 1.34 \\
3 & 0.86 & 0.86 \\
4 & 1.21 & 1.52 \\
7 & 1.43 & 1.28 \\
$5 / 6 / 8$ & 0.93 & 0.94 \\
\hline
\end{tabular}

*Calculated as the ratio of the antigen frequency in pre-eclampsia patients to controls.

\#Ratio of T.NFo secretory capacity to the average value, calculated from data provided by Pociot et al. (1993).

Table 2. Putative high TIF responders in pre-eclampsia patients and controls after exclusion of all subject with HL.A-DRt.

\begin{tabular}{lcc}
\hline & DR1 or DR3 positive $(\%)$ & Significance \\
\hline $\begin{array}{l}\text { Pre-eclampsia patients } \\
(\mathrm{n}=58)\end{array}$ & 69 & - \\
$\begin{array}{l}\text { Female controls } \\
(\mathrm{n}=51)\end{array}$ & 48 & $\mathrm{p}<0.01$ \\
$\begin{array}{l}\text { Total (male+female) control } \\
(\mathrm{n}=91)\end{array}$ & 46 & $\mathrm{p}<0.002$ \\
\hline
\end{tabular}

4 possessing subject. It is notew orthy that the positive association was still evident after this amendment.

Although there is an unexplained association between pre-eclampsia and type 1 diabetes. most diabetic, do not experience pre-eclampsia during pregnancy and only a small proportion of pre-eclampsia patients subsequently develop diabetes. These circumstances suggest that pre-eclampsia and diabetes are distinct diseases with separate causes, yet with some relevant common factor linking the two. A tendency to produce a high level of TNF in response to (presumably different) stimuli could be the common factor.

We found no single DRt-bearing haplotype to be over-represented in pre-eclampsia (Liston and Kilpatrick. 1991) and others have failed to find any linkage between preeclampsia and the maternal HLA-DR region (Wilton et al., 1991; Hayworth et al., 1992). If the suggestion made here be true, it is not necessary to invoke HLA-DR as being linked to a disease susceptibility gene. Instead, HLA-DR4 (and other $\mathrm{DR}_{\beta}$ alleles) would function as immune response genes, modulating the TNF $\alpha$ response to (unspecified) stimulation. Such HLA associations would presumably be in addition to, and independ- 
ent of, other disease susceptibility genes. HLA would be part of a more complex genetic susceptibility, which would also include a fetal contribution (Liston and Kilpatrick, 1991). It might be worthwhile for other workers with HLA data in pre-eclampsia to reexamine their HLA-DR data in the light of this analysis.

\section{REFERENCES}

Bendtzen, K., Morling, N., Fomsgaard, A., Svenson, M., Jakobsen, B., Odum, N., Svejaard, A. (1988). Association between HLA-DR2 and production of tumour necrosis factor $\alpha$ and interleukin 1 by mononuclear cells activated by lipopolysaccharide. Scan. J. Immunol., 28, 599606.

Cooper, D.W., Brennecke, S.P., Wilton, A.N. (1993). Genetics of pre-eclampsia. Hypertension in Pregnancy, 12, 1-23.

Dahlquist, G., Källén, B. (1992). Maternal-child blood group incompatibility and other perinatal events increase the risk for early-onset Type 1 (insulin-dependent) diabetes mellitus. Diabetologia, 35, 671-675.

Garner, P.R., d'Alton, M.E., Dudley, D.K., Huard, P., Hardie, M. (1990). Pre-eclampsia in diabetic pregnancies. Am. J. Obstet. Gynecol., 163, 505-508.

Hayward, C., Gilfillan, A., Livingstone, J., Adam, M., McIntosh, I., Brock, D.J.H. (1990). HLADR and pre-eclampsia in Edinburgh. Lancet, 335, 1458-1459.

Hayward, C., Livingstone, J., Holloway, S., Liston, W.A., Brock, D.J.H. (1992). An exclusion map for pre-eclampsia: assuming autosomal recessive inheritance. Am. J. Hum. Genet., 50, 749-758.

Jacob, C.O., Fronek, Z., Lewis, G.D., Koo, M., Hansen, J.A., McDevitt, H.O. (1990). Heritable major histocompatibility complex class II-associated differences in production of tumour necrosis factor $\alpha$ : relevance to genetic predisposition to systemic lupus erythematosus. Proc. Natl. Acad. Sci. USA, 87, 1233-1237.

Jazwinska, E.C., Kilpatrick, D.C., Smart, G.E., Liston, W.A. (1987). Feto-maternal HLA compatibility does not have a major influence on human pregnancy except for lymphocytotoxin production. Clin. Exp. Immunol., 69, 116-122.

Kilpatrick, D.C., Gibson, F., Livingstone, J., Liston, W.A. (1990). Pre-eclampsia is associated with HLA-DR4 sharing between mother and fetus. Tissue Antigens, 35, 178-181.

Liston, W.A., Kilpatrick, D.C. (1991). Is genetic susceptibility to pre-eclampsia conferred by homozygosity for the same single recessive gene in mother and fetus? Br. J. Obstet. Gynaecol., 98, 1079-1086.

Peces, R., Urra, J.M., de la Torre, M. (1995). Influence of HLA-DR phenotype on tumour necrosis factor-alpha production in renal transplant recipients. Nephron, 71, 180-183.

Pociot, F., Briant, L., Jongeneel, C.V., Mölvig, J., Worsaae, H., Abbal, M., Thomsen, M. Nerup, J., Cambon-Thomsen, A. (1993). Association of tumour necrosis factor (TNF) and class II major histocompatibility complex alleles with the secretion of TNF $\alpha$ and TNF $\beta$ by human mononuclear cells: a possible link to insulin-dependent diabetes mellitus. Eur. J. Immunol., 23, 224-231.

Santamaria, P., Gehry, R.C., Bryan, M.K., Barbosa, J.J. (1989). Involvement of Class II MHC molecules in the LPS-induction of IL-1/TNF secretions by human monocytes. J. Immunol., 143, 913-922.

Simon, P., Fauchet, R., Pilorge, M., Calvery, C., Le Fiblec, B., Cam, G., Ang, K.S., Genetet, B., Cloup, B. (1988). Association of HLA-DR4 with the risk of recurrence of pregnancy hypertension. Kid Int., 34, Suppl. 25, 5125-5128.

Stark, J.M. (1993). Pre-eclampsia and cytokine induced oxidative stress. Br. J. Obstet. Gynaecol., 100, 105-109.

Wilton, A.N., Barendse, W.J., Donald, J.A., Marshall, P., Trudinger, B., Gallery, E.D.M., 
Brennecke, S.P., Cooper, D.W. (1991). HLA-DR $\beta$ types in pre-eclampsia and eclampsia. Tissue Antigens, 38, 137-141. 


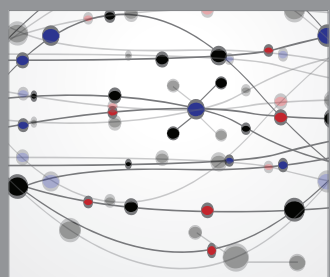

The Scientific World Journal
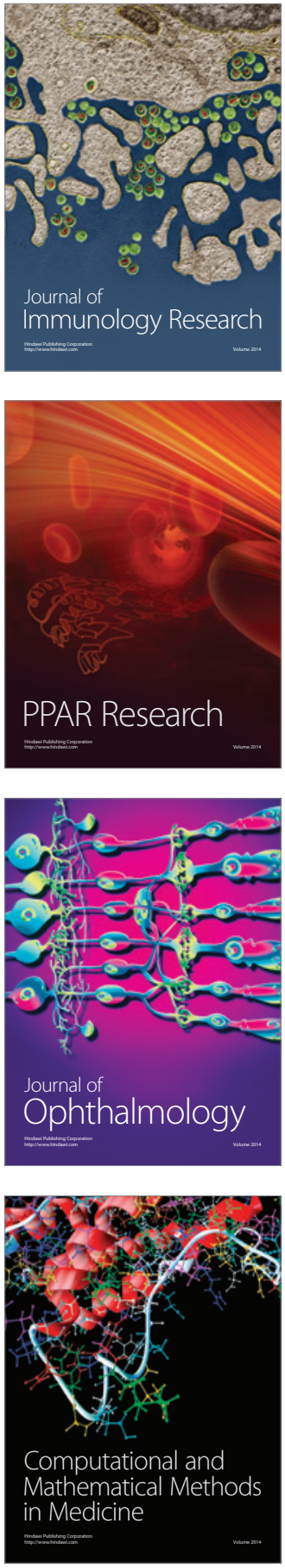

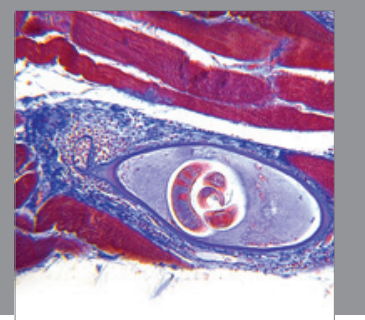

Gastroenterology

Research and Practice
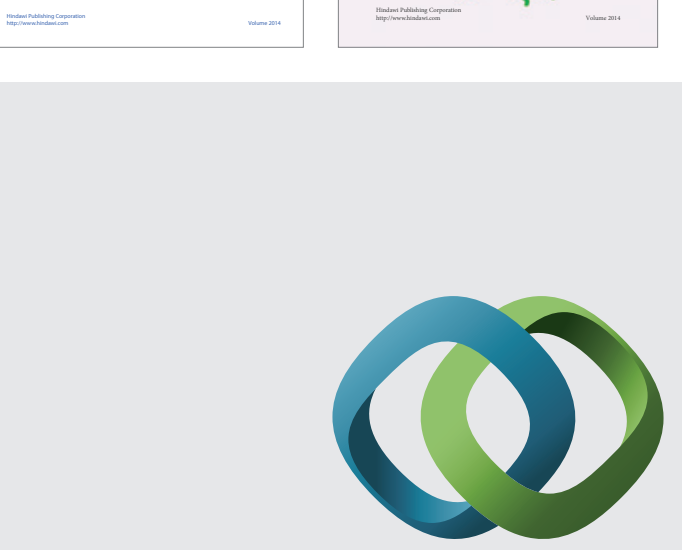

\section{Hindawi}

Submit your manuscripts at

http://www.hindawi.com
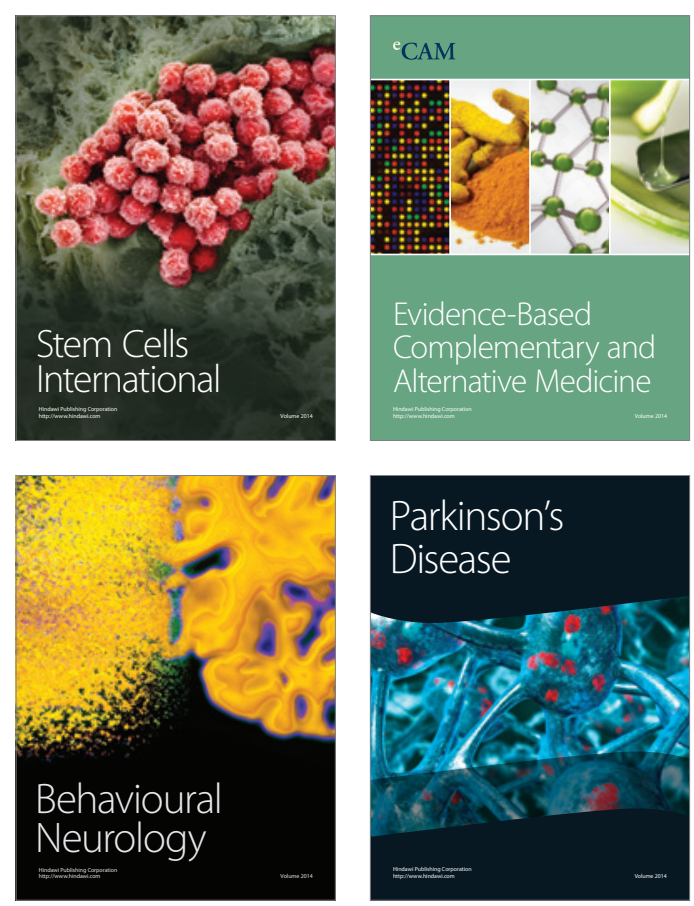

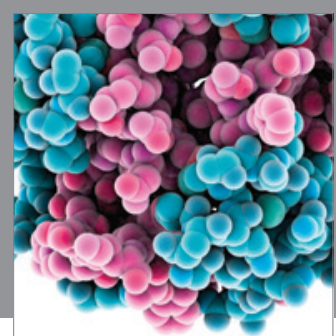

Journal of
Diabetes Research

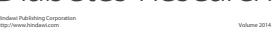

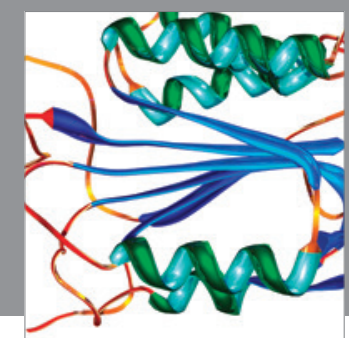

Disease Markers
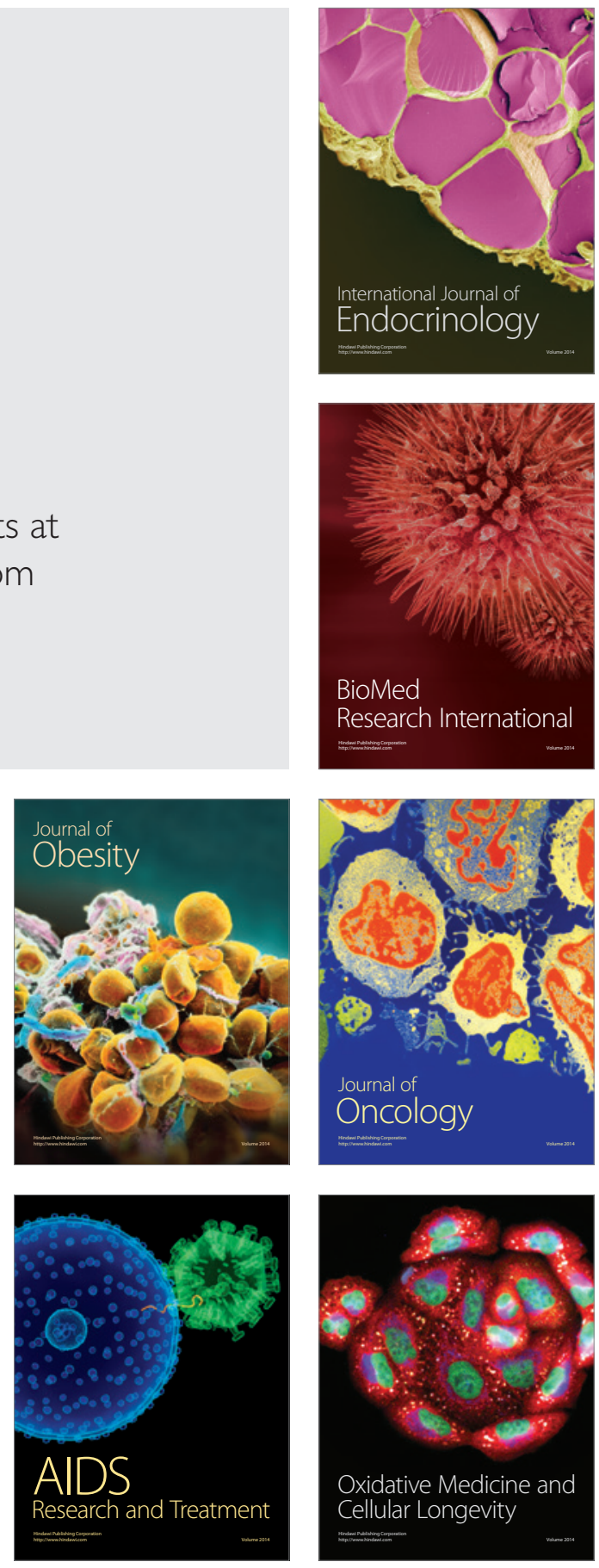